\title{
Community perceptions of a rural medical school: a pilot qualitative study
}

This article was published in the following Dove Press journal:

Advances in Medical Education and Practice

7 November 2014

Number of times this article has been viewed

\section{Debra Nestel' \\ Katherine Gray' \\ Margaret Simmons' \\ Shane A Pritchard' \\ Rumana Islam' \\ Wan Q Eng' \\ Adrian $\mathrm{Ng}^{\prime}$ \\ Tim Dornan ${ }^{2}$}

'Gippsland Medical School/School of Rural Health, Monash University, Clayton, Australia; ${ }^{2}$ School of Health Professions Education, Maastricht University, Maastricht, the Netherlands
Correspondence: Debra Nestel Gippsland Medical School/School of Rural Health, Building I3, Room 42 Clayton, 3800 Australia

Tel +6I 404465959

Email debra.nestel@monash.edu
Background: This paper explores local community perceptions of a relatively new rural medical school. For the purposes of this paper, community engagement is conceptualized as involvement in planning, delivering, and evaluating the medical program. Although there are several reviews of patient involvement in medical curricula development, this study was designed to pilot an approach to exploring the perspectives of well members of the community in the transition of institutional policy on community engagement to one medical school.

Methods: An advertisement in the local newspaper invited volunteers to participate in a telephone interview about the new medical school. An independent researcher external to the medical school conducted the interviews using a topic guide. Audio recordings were not made, but detailed notes including verbatim statements were recorded. At least two research team members analyzed interview records for emergent themes. Human research ethics approval was obtained.

Results: Twelve interviews were conducted. Participants offered rich imaginings on the role of the school and expectations and opportunities for students. Most participants expressed strong and positive views, especially in addressing long-term health workforce issues. It was considered important that students live, mix, and study in the community. Some participants had very clear ideas about the need of the school to address specified needs, such as indigenous health, obesity, aging, drug and alcohol problems, teenage pregnancy, ethnic diversity, and working with people of low socioeconomic status.

Conclusion: This study has initiated a dialogue with potential partners in the community, which can be built upon to shape the medical school's mission and contribution to the society it serves. The telephone interview approach and thematic analysis yielded valuable insights and is recommended for further studies. Our study was limited by its small study size and the single recruitment source. The community is a rich resource for medical education, but there is a dearth of literature on the perspectives of the community and its role in medical education.

Keywords: community engagement, medical education, medical school, community-based education, rural, curriculum development

\section{Introduction}

Community engagement is frequently cited as an important mission of higher education institutions. The values of the authors" own institution include a "commitment to a wide range of professional and community activities." The sociological literature suggests that community engagement assists in addressing community problems while considering the motives, intentions, and purposes of the government, business, 
and community sectors. ${ }^{2}$ Community engagement in health promotion is

the process of working collaboratively with and through groups of people affiliated by geographic proximity, special interest, or similar situations to address issues that affect the well-being of those people. ${ }^{3}$

Several terms are used in the medical education literature to describe community engagement; we describe community/ lay/public engagement as direct and indirect involvement in planning, delivering, and evaluating the medical program. Strasser describes community engagement in a medical education setting as the integration of a medical school and its surrounding community in a partnership where students' learning experiences are enhanced, while the demands for community-based care are addressed. ${ }^{4}$

Drivers of community engagement in medical curricula include worldwide health policy obligations, ${ }^{5}$ pressure on clinicians to prioritize clinical care at the expense of clinical education, ${ }^{6}$ emphasis on patient "rights" and free choice limiting opportunities for students to practice skills with patients, ${ }^{6}$ realization of inappropriate caseloads for students at urban tertiary teaching hospitals, ${ }^{6,7}$ and the discovery that only a small proportion of the population receive health care in large acute teaching hospitals. ${ }^{8}$ Demands for community involvement in medical education are particularly high in rural communities where there is an ongoing shortage of rural health practitioners within a growing rural population, despite the innovative measures that have improved the distribution of medical practitioners. ${ }^{9}$

Prideaux et al describe a "symbiotic" medical curriculum to explain the mutualistic relationship between medical schools and health services. ${ }^{6}$ The quality of community-based health care benefits from the contribution of medical students and staff while students experience effective learning opportunities. ${ }^{6}$ Four primary relationships guide symbiotic medical education: students' personal values of clinical practice and the profession's expectations; clinicians and patients; the students' educational institution and its associated health services, and government educational policy and funding; and the expectations of the local community on health service provisions. ${ }^{6}$ Medical student learning outcomes can be greater and students' perceptions of the value of their education can be enhanced when medical ${ }^{10}$ education is community-based and when the student is in the center of these relationships. ${ }^{6,11}$

A review of service user involvement in medical education specifically concerning "real patients" revealed two of 47 studies (pre July 2007) that accessed respondents from the wider community and not patients previously engaged in health care programs. ${ }^{12}$ A second review of involvement in the education of health professionals identified eleven studies (pre July 2006) that reported service users' views informing curriculum development rather than curriculum delivery, assessment, or program evaluation. ${ }^{13}$ Two studies were in undergraduate medical education. ${ }^{14,15}$ The first study reported involving minority ethnic groups in Birmingham, UK, to enhance minority engagement in curriculum planning; ${ }^{15}$ the second study detailed curriculum content for psoriasis. ${ }^{14}$ A third paper published outside the time frame of these two reviews explored how best to increase lay involvement in curriculum development. ${ }^{16}$ Service users who participated in focus groups recommended newspaper advertisements as the best means of accessing lay opinion. This study was limited in as much that it was through newspaper advertisements that respondents had, themselves, been recruited. ${ }^{16}$

The benefits of community engagement in medical education for students, medical schools, and the community are well described in the literature; the perspectives of the community's role in medical education are not. Examples of community engagement in medical education usually describe community involvement at the implementation stage of curriculum ${ }^{17}$ rather than planning or evaluation stages. Interventions also do not consider how we measure success of a medical school from a community perspective.

Gippsland Medical School (GMS) is located in a rural area of the Latrobe Valley, approximately 150 kilometers east of the state capital in Victoria. The population is approximately 75,000, with significant clusters in three centers (Moe, Morwell, and Traralgon) and smaller settlements in Churchill (site of GMS), Yinnar, Glengarrie, and Tyers. ${ }^{18}$ With a mixed industry base, the local economy is based on power generation (brown coal), supplying the majority of the state's electricity. Additionally, there are a range of manufacturing industries related to forestry and agricultural resources. The median age of the population is 38 years (younger than the rest of the state), the unemployment rate is about $6.4 \%$ (higher than the rest of the state), and formal levels of education are lower than the rest of the state. ${ }^{18}$

The graduate entry medical program was commenced in 2008 at GMS, Monash University, with the goal of providing a curriculum that prepared students to enter a changing health workforce. The delivery of significant components of the program in rural areas was considered important in orienting graduates to careers in the rural health workforce. In order to establish an experimental framework to explore the translation of institutional policy on community engagement, 
we sought the perceptions of GMS from members of the local community. Specific research questions were "in what ways can GMS engage with its local community?"; and "what are the community's expectations of GMS students while completing their medical degree and upon graduation?"

\section{Materials and methods}

In order to address the research questions, individual telephone interviews were deemed the most feasible method. A professional market researcher (male) external to the university and very experienced in interviewing was contracted to conduct the interviews. He was unknown to the interviewees. Telephone interviews were scheduled so data collection could be conducted at a mutually agreeable time with no travel involved and with minimal expense. A topic guide was developed and piloted within GMS (Figure S1). Telephone calls were not recorded. The external researcher made detailed notes during the interaction, including several verbatim statements made by the interviewee. If the interviewee was not available at the scheduled time of the interview, two further attempts were made to contact the interviewee. With a time-limited period in which to conduct the interviews, there was a risk that we would not reach data saturation in the interviews. However, since we were exploring an approach to capturing the views of community members, this was less critical than if this was presented as a definitive study.

Individuals living in the Latrobe Valley community, where GMS is situated, were eligible to participate. Potential interviewees responded to an advertisement in a regional newspaper. The advertisement sought volunteers to participate in a telephone interview about "medical student training in the Latrobe Valley, Gippsland." Potential interviewees were asked to telephone a named person at GMS for further information. Callers were provided with a full explanation of the project, and sent an explanatory statement and consent form. All callers continued in the process after the verbal explanation. The interviewer scheduled a telephone interview for the week following receipt of the interviewee's signed consent form. Fifteen callers responded to the advertisement. Three were unavailable for interviews because they could not be contacted within a total of three time-distributed calls.

We were interested in learning about the lived experiences of the Latrobe Valley community and so we adopted a phenomenological approach. Our research team adopted a constructivist/interpretivist paradigm to make meaning of the experiences of interviewees. We thematically analyzed the data. ${ }^{19-21}$ All researchers participated in the data analysis.
Each interview was analyzed by at least two researchers who extracted themes derived from the data. Transcripts were read independently with each researcher identifying main themes. At least two researchers then read each data set, again seeking confirming or disconfirming data. There were few disagreements during analysis. Those that occurred were associated with the weight of meaning rather than direction. The research questions probably influenced the way in which we interpreted the data as they were closely linked with the topic guide. While two of the research team members were external to GMS (SP, TD), the rest held roles at GMS as faculty (DN, KG, MS) and students (RI, WE, AN). Insider and outsider perspectives with respect to GMS and for insiders, our different functions at GMS, offered valuable insights. However, even with our varied perspectives, there was strong consensus in identifying main themes. Approval for the study was obtained from the Monash University human research ethics committee (Reference CF09/0497-2009000180).

\section{Results}

Twelve telephone interviews were conducted, each lasting 5-28 (median 17) minutes. Seven females and five males aged 25-82 (mean 45) years who reported living in the Latrobe Valley region for 5-60 (mean 33) years were interviewed. Five participants were retired, listing their former occupations as farmer, school principal, nurse, pilot, and civil servant. Other participants were currently employed as a health information officer, disability service officer, homemaker, town planner, fireman, and cleaner. One participant did not answer this question. The main themes were: knowledge and involvement with GMS; GMS engagement and serving local communities; students interacting with patients and doctors; and measuring the success of GMS.

\section{Knowledge and involvement with GMS}

Participants reported that they learned of the existence of GMS through newspaper articles and advertisements. One participant had encountered a medical student at a general practice clinic, one knew of a local student attending GMS, and another had heard about "the new medical school" through a social conversation. All participants knew GMS existed, but offered very little specific knowledge about the school. Several participants hypothesized that GMS was established to help develop a medical workforce for the region. One participant suggested that GMS was established to ensure "students stay in and circulate in our community" (Interviewee 1). Another participant stated GMS was “... a training area for doctors who are nearly finished uni" 
(Interviewee 2). One participant suggested that GMS “ ... runs training sessions and experienced practical training for third year medical students" (Interviewee 11).

\section{GMS engagement with and serving local communities}

Nine participants emphasized the importance of students and staff mixing with the local community when asked how GMS can best engage with and serve local communities. Living, studying, and working in the local community were considered to be invaluable experiences for medical students. Participants also articulated that GMS could serve local committees by targeting specific local needs, including: indigenous health, obesity, aging, drug and alcohol problems, teenage pregnancy, ethnic diversity, and working with people of low socioeconomic status. Three participants stated that they did not know how GMS could best serve the local community.

One participant suggested it was the responsibility of GMS to keep the community informed of their progress, particularly through local media. Others suggested that the community had much to offer and therefore deserved to be involved. However, there were few specific suggestions as to what this involvement should be. One interviewee, in response to being questioned about how GMS could support the community, suggested

[...] mental health support, you need to understand the consumer ... to help doctors, general practitioners, to recognize the condition ... I have mental illness and we need more help out in the community. Doctors don't get enough training with real people with mental health problems. They need to sit down with us, with people with mental health problems who can talk about what it's really like. There is a great need for the people from the valley to help out. By using us, the consumers, people who are educated, in jobs and who have lived in these communities and with these issues [...] we can help train the doctors, case workers [...] (Interviewee 1).

When asked to identify ways in which GMS might best serve the local community, the same interviewee proposed

having trainee doctors at different medical clinics, or a trainee medical center like a trainee hairdresser set up for cheaper advice and different levels of care according to their expertise (Interviewee 1).

Another interviewee suggested that GMS should engage with the local community by putting on displays of their expertise, having open days, maybe brochures and things like that, things they can do (Interviewee 9).

\section{Students interacting with patients and doctors}

Consistent themes expressed in response to questioning about important skills that medical students should demonstrate when interacting with patients included listening, showing empathy and respect, adopting positive attitudes, asking permission to examine patients, and giving good quality information. One participant suggested that rural doctors have a different experience to those in the city

A rural doctor spends more time with their patients than city doctors and are more aware of family situations, they give a more rounded level of care. (Interviewee 9).

\section{Measuring the success of GMS}

Participants were asked to postulate how the success of GMS into the future could be demonstrated. Participants reported that indicators of success included the active involvement of GMS in the local community, GMS-qualified doctors choosing to work in Gippsland upon graduating, and improved health in the local community: "more awareness of medical issues, healthier communities, less need for hospital admissions because we're proactive" (Interviewee 5).

One participant suggested that a survey on the quality of graduating doctors be used to measure success of GMS. Another stated that "providing all the doctors we need in the valley and not have to go to Melbourne for care" (Interviewee 12) would indicate success. Alternatively, one participant believed "government policies will have more impact than GMS” (Interviewee 10).

\section{Discussion}

An attempt to explore the perceptions of a medical school through the lenses of lay people in the school's local community has provided a platform for enhanced community input to the school. Although few in number, people who varied widely in age, occupation, and amount of time spent living in the region accepted the invitation to share how they thought a new medical school could contribute to the health of people in its catchment population. Although all respondents were aware of GMS, few were aware of the large focus GMS has on community integration. Most expressed a strong desire to see the activities of GMS integrated with the local community. 
Highly individual and sophisticated narrative accounts of participants' expectations of and wishes for a medical school were provided. The primary expectations of GMS included addressing health needs relatively specific to its local community and the mental health needs inadequately met by existing health services. Specific attributes and behaviors that participants expected of doctors graduating from GMS and benchmarks against which the success of the school could be judged were also voiced.

Participants demonstrated greater ease in establishing the attributes of a medical school that successfully engages with the local community than providing specific examples on how to achieve this. However, student-led clinics, raising the profile of mental health, promoting activities and achievements of GMS, students immersing their personal lives in the local community, and providing opportunities for community members to contribute to the life of the medical school and students, were suggested as possible approaches.

First year students at GMS already participate in the subject "Health and Society", which seeks to recognize and reflect the rural context within which students are taught. In addition, students also complete a block of community placements with various local agencies where they are heavily involved in community engagement. ${ }^{17}$ A separate indigenous health module is also undertaken to appreciate the complexities of indigenous health. Many of the issues expressed by participants in this study are addressed by this content, suggesting that although GMS is already attempting to respond to the perceived needs of the community (as articulated in this study), more may be required to "advertise" GMS.

A review of the relevant literature showed one other study designed to allow the voices of lay people to be heard in curriculum development. ${ }^{16}$ The main focus of this paper was on how those voices could be heard, rather than on what issues were important to unselected members of a community served by a medical school. ${ }^{16}$ Nevertheless, that study identified service users' wishes for medical students to learn good communication skills, counseling skills, and an ability to negotiate treatment plans with patients. Since the patient-centered method $^{22}$ is already widely taught in medical schools, this study adds to the findings of O'Keefe and Jones ${ }^{16}$ by showing how health issues of specific concern to the population served by a medical school can be highlighted in a way that could steer curriculum development. In other words, our case study shows how community health needs could steer curriculum strategy in ways that are meaningful and responsive to specific local community needs. A recent review of service user involvement in medical education established that the purpose of involving lay people is to fulfill the social accountability of higher education institutions. ${ }^{23}$ Towle and Godolphin characterize this as a "moral imperative." ${ }^{23}$ Service user involvement, according to them, is one component of a pentad of partnerships that underpin social responsibility and a patient needs-based health system. ${ }^{23}$ The concept of public and patient involvement in the health services is apparent at all stages of new developments in the National Health Service in the UK. Rhetoric on the Australian health care system is less explicit about public and patient involvement, although it is common to have lay representation at governance and regulatory levels. In the UK and Australia, public and patient involvement is largely confined to the implementation phase in medical education, and there may be potential benefits to shifting this focus.

\section{Strengths and limitations of the study}

Due to a recruitment protocol not involving existing health services, the major strength of this study is that an opportunity to share perceptions of a medical school was provided to any interested person. Respondents' concerns could be identified and explored in a neutral way since the interviewer was not a health professional. The sample size was too small for data to be representative of concerns of the wider population, but, as a pilot design experiment in community engagement, this study is illustrative of what could be achieved by opening up further dialogue with members of society. Therefore, we offer our conclusions with caution.

There are several limitations to this study. The responses of participants may not represent broader community views due to the small sample size and larger proportion of retirees in the sample compared with the region. All interviewees were readers of the same local paper and attended to the advertising column, which may not represent the practices of the wider local community. Education levels of the regional population are relatively low and so it is likely that the literate population who read and responded to the advertisement have particular views. The study was conducted within a strict time frame and budget, so data collection ceased prior to identification of data saturation. This is a major limitation in making meaning of the results. However, the pilot is intended as a beginning conversation with the community and not an endpoint. GMS is also a relatively new and rural-based medical school, and so may not have relevance to established and metropolitan schools. Nevertheless, we were able to 
balance constraints of the human research ethics committee, with the collection of meaningful data with relatively little expense. We eliminated costs to respondents through initiatives such as no travel, mutually convenient interview times, self-addressed stamped envelopes, and GMS telephone call expense. Detailed notes were used rather than transcribed audio recordings in analysis. These limitations are considered in our research conclusions.

\section{Conclusion}

This study demonstrates that it is feasible to open a communication pathway between service users and a medical school that is, in principle at least, open to any interested party. It is evident by the willing and informed responses that this pathway is both feasible, and associated with service user interest. However, this study is a pilot concept study and now calls for a mechanism to be developed that enables service user interests and concerns to shape the policy and practice of an undergraduate medical school. A preliminary step is to seek funding to support a larger interview or focus group study that probes these emergent themes and explores the views of the wider community. Future research may include an action research design to test other ways of connecting the medical school with service users, gathering opinion, integrating the views of service users into curriculum development, and making the process transparent to demonstrate to the community that its concerns are of value. Engagement is two-way, so strengthening structural and functional processes that support community involvement at all stages of our curriculum from selection, planning, implementation, and evaluation seems appropriate.

\section{Author contributions}

DN developed the concept of the study. All authors contributed to analysis of the data and preparation of the manuscript, and read and approved the final draft.

\section{Disclosure}

The authors declare that they have no conflicts of interest in this work.

\section{References}

1. Monash University. Monash University Faculty of Medicine, Nursing and Health Sciences: values, vision and strategic goals. 2012. Available from: http://www.med.monash.edu.au/values-vision-goals.html. Accessed October 25, 2012.

2. Head BW. Community engagement: participation on whose terms? Aust J Polit Sci. 2007;42:441-454.
3. Centers for Disease Control and Prevention. Principles of community engagement. Atlanta, GA, USA: CDC/ATSDR Committee on Community Engagement; 1997. Available from: http://www.atsdr.cdc. gov/communityengagement/. Accessed September 3, 2014.

4. Strasser RP. Community engagement: a key to successful rural clinical education. Rural Remote Health. 2010;10:1543-1549.

5. World Health Organization. Ottawa charter for health promotion. Can J Public Health. 1986;77:426-430.

6. Prideaux D, Worley P, Bligh J. Symbiosis: a new model for clinical education. Clin Teach. 2007;4:209-212.

7. Worley P, Silagy C, Prideaux D, Newble D, Jones A. The Parallel Rural Community Curriculum: an integrated clinical curriculum based in rural general practice. Med Educ. 2000;34:558-565.

8. Green LA, Fryer GE, Yawn BP, Lanier D, Dovey SM. The ecology of medical care revisited. $N$ Engl J Med. 2001;344:2021-2025.

9. Australian Government Department of Health and Ageing. Report on the Audit of Health Workforce in Rural and Regional Australia. Canberra, Australia: Commonwealth of Australia; 2008. Available from: http://www.health.gov.au/internet/publications/publishing.nsf/ Content/work-res-ruraud-toc. Accessed September 3, 2014.

10. Worley P, Esterman A, Prideaux D. Cohort study of examination performance of undergraduate medical students learning in community settings. BMJ. 2004;328:207-209.

11. Worley P, Prideaux D, Strasser RP, Magarey A, March R. Empirical evidence for symbiotic medical education: a comparative analysis of community and tertiary-based programmes. Med Educ. 2006;40: 109-116.

12. Jha V, Quinton ND, Bekker HL, Roberts TE. Strategies and interventions for the involvement of real patients in medical education: a systematic review. Med Educ. 2009;43:10-20.

13. Morgan A, Jones D. Perceptions of service user and carer involvement in healthcare education and impact on students' knowledge and practice: a literature review. Med Teach. 2009;31:82-95.

14. Ahlalafi A, Burge S. What should undergraduate medical students know about psoriasis? Involving patients in curriculum development: modified Delphi technique. BMJ. 2005;330:633-636.

15. Greenfield SM, Anderson P, Gill PS, et al. Community voices: views on the training of future doctors in Birmingham, UK. Patient Educ Couns. 2001;45:43-50.

16. O'Keefe M, Jones A. Promoting lay participation in medical school curriculum development: lay and faculty perceptions. Med Educ. 2007;41:130-137.

17. Mudarikwa RS, McDonnell JA, Whyte S, et al. Community-based practice program in a rural medical school: benefits and challenges. Med Teach. 2010;32:990-996.

18. Latrobe City Council. Latrobe City Economic and Population Indicators. 2014. Available from: http://www.latrobe.vic.gov.au/Our_Community/ Who_Lives_in_Latrobe/Population_and_Economic_Profile. Accessed July 30, 2014.

19. Saldana J. The Coding Manual for Qualitative Researchers. 2nd ed. London, UK: Sage Publication; 2013.

20. Braun V, Clarke V. Using thematic analysis in psychology. Qual Res Psychol. 2006;3:77-101.

21. Miles M, Huberman A, Saldana J. Qualitative Data Analysis: A Methods Sourcebook. 3rd ed. Los Angeles, CA, USA: Sage Publications; 2014.

22. Stewart M, Brown JB, Weston WW, McWhinney IR, McWilliam CL, Freeman TR. Patient-Centred Medicine: Transforming the Clinical Method. Thousand Oaks, CA, USA: Sage Publications; 1995.

23. Towle A, Godolphin W. Patient involvement in health professional education. In: Dornan T, Mann K, Scherpbier A, Spencer A, editors. Medical Education: Theory and Practice. Edinburgh, UK: Churchill Livingstone; 2010. 


\section{Supplementary material}

1. How did you learn about the existence of Gippsland Medical School (GMS)?

2. Do you have any involvement in GMS? If so, what is that involvement?

3. Do you know anyone associated with GMS? If so, what is their role?

4. What do you know about GMS?

5. How best do you think GMS can engage with Gippsland communities?

6. How best do you think GMS can serve the needs of Gippsland communities?

7. Is there anything you think we need to be aware of in relation to serving local communities? If so, what?

8. When interacting with patients (in hospitals, general practices, etc), what do you think are important things for students to consider?

9. How do you think we can measure the success of GMS?

10. If you think about Gippsland 10 years from now (think about 2020), what impact do you think GMS might have had in Gippsland?

11. Is there anything else you would like to say about GMS?

12. Do you have any other comments?

Finally, could you answer the following questions:

- How long have you lived in Gippsland?

- What sex are you?

- How old are you?

- What is your current (or most recent) occupation?

Figure SI Topic guide for telephone interview.

\section{Publish your work in this journal}

Advances in Medical Education and Practice is an international, peerreviewed, open access journal that aims to present and publish research on Medical Education covering medical, dental, nursing and allied health care professional education. The journal covers undergraduate education, postgraduate training and continuing medical education including emerging trends and innovative models linking education, research, and health care services. The manuscript management system is completely online and includes a very quick and fair peer-review system. Visit http://www.dovepress.com/testimonials.php to read real quotes from published authors.

Submit your manuscript here: http://www.dovepress.com/advances-in-medical-education-and-practice-journal 